\title{
Excerpted from:
}

ETHICS OF TECHNICAL CHANGE: THE CASE OF BST

\section{Jeff Burkhardt, Food and Resource Economics, University of Florida}

Recombinant Bovine Somatotropin (BST) has been the subject of controversy for over five years. Most if not all of the potential scientific, political, economic, and ethical risks and benefits associated with widespread use of the compound are well-documented. Yet, as is evidenced by the continuing stream of professional journal and newspaper articles, and workshops and symposia around the world, the issues associated with BST remain topics of heated debate. There are several reasons for this. That BST is one of the first commercially-feasible products from biotechnology is certainly part of the case. There are, however, many more important dimensions to "The Case of BST" than its biotechnology connection.

One important condition in this regard is the larger society's "philosophy of technology' which serves to guide both individual and institutional decisions. One such philosophy - to be referred to as "productionism"-has come to dominate decisions about both agriculture and agricultural research. Although there are strong historical as well as ethical reasons behind the productionist idea, this view has come under increasing philosophical (as well as political) attack. It is at this philosophical level that the major ethical concerns pertaining to the case to BST are raised. For, in the face of ethical challenges to productionism, we, as individuals and as a society, must again decide whether "more technology" and "more products" are to remain social and individual goals. For many social analysts, and in many governmental accounts of future possibilities for our society's technological mode, there seems to be an assumption that particular kinds of changes are inevitable. The focus on "trends," "tracks" and "outcomes" suggests that particular kinds of change will occur.

As important as the notion of choice is in the analysis of technical change, it is a mistake to think that all particular technical changes are the result of planning or conscious design. Technical changes occur for a variety of reasons, motives and beliefs, not all of which are calculated, planned and informed. The notion of a "technology treadmill" is understandable in this light. In effect, because of our prior decisions and the decisions of others, we must choose technical change. As the stream of new technologies continues, we will continue to have to make those choices.

At the individual level, "the ethics of technique" pertains to the actual practice of using a tool or technique. The ethics associated with change in technique at this level are principles governing learning about and monitoring the use of 
the new tool or strategy, so that bad consequences are avoided.

"Technical ethics" also covers the decisions groups of individuals make to adopt techniques in the first place: is the choice of a particular "new" technique or tool justifiable from the point of view of the array of ethical values which surface in an individual's interactions and connections with others in a larger community?

A third dimension of the ethics of technique involves the decisions groups of individuals make to allow or legitimize the adoption of new techniques on a larger societal scale. Decisions of this sort are made by "invisible hands" or "visible hands." For a variety of ethical reasons (including freedom of choice), markets are judged to produce the"best results": markets deliver what consumers want, for whatever reasons they want, including ethical (and unethical) reasons.

Markets only deliver or governments only authorize techniques or products which have already been at least conceptualized. The fourth dimension of "technical ethics" thus concerns the decisions individuals or groups make with respect to research on and development of new techniques and alternative ways of doing things. The judgement that a particular technique or tool should be developed in the first place is certainly made in the hope or expectation that it will be "induced" into a political-economic system once developed. "Economic" interests in the success or profitability of the new technique undoubtedly predominate. The value-context (e.g., "mission") of research institutions themselves is also relevant, as is whether or not the decisions are made in private, or in the public arena. This reflects consideration of ethical values subscribed to by the larger society: toward what techniques are potential consumers and the larger public disposed?

The last and broadest dimension of the "ethics of technical change" pertains to the larger society's beliefs and dispositions toward new techniques. What dictates our willingness to accept, promote, certify, adopt and use new tools, technologies, or techniques? What principles explicitly or implicitly lead us to ratify particular kinds of technical changes? A basic question is: upon what principles and values do we j udge even our basic philosophy of technology to be right or good?

The case of BST is a good "ethics case" with regard to technical change, for it includes all of the dimensions of individual and group decision-making, institutional legitimacy, and fundamental philosophy, although the last may be less than transparent at first sight.

The case of BST is standardly invoked in discussions of the ethics of the "new biotechnology", and genetic engineering in particular. This can be misleading. While BST is a product of procedures which involve genetic engineering, most 
of the issues associated with the case of BST are independent of its biotechnology connection. Of course, if there are major ethical problems associated with biotechnology per se, recombinant BST is not significantly different from "natural" BST harvested from the pituitary glands of cows. Unless we ethically reject all such "bioproducts," BST remains but a "new technology" in the broadest sense of that term. Ethical principles apply to the case of BST just as they apply to other new technologies, e.g., computer software.

The "ethics of technique" is raised initially in connection with the question of whether there is a right way and a wrong way to use BST. Analysts of BST have repeatedly noted that a significant change in "management" is associated with BST use: individualized dosages, careful monitoring, etc. This is significant from the point of view of economics and also from the point of view of ethics: BST carries with it some "rules."

The major ethical question associated with individual choice about BST is, however, whether there really is a choice. It may be that the economic and social situation in which farmers find themselves unfairly limit their opportunities for choosing alternative techniques. However, it would appear that farmers do have a choice not to use BST. That they choose to do so suggest that they have accepted the conditions historically prior to and philosophically behind the introduction of BST.

Most of the literature pertaining to the case of BST has focused on the "social ethics" features of BST legitimation and creation. The question of the "marketing of BST" and the responsibility of federal government agencies (USDA, EPA, FDA), state governments (e.g., Wisconsin, Minnesota) and the courts in deciding the legitimacy of the diffusion of this technique is of course a major element in this story. The conflict-ridden interactions of people, as well as the economic and ethical values undergirding the conflicts pertain to two basic questions: Why BST? Why not BST?

In the political sphere and in the larger public forum, the "case against BST" has been pressed by coalitions of dairy farmers, animal rights activists, the Foundation on Economic Trends, and most recently, the Consumer's Union. The arguments range from those highlighting the likely negative socio-economic effects on classes of dairy farmers, to indictments of the potential negative human and animal health effects, to larger questions about society's "permitting" biotechnologically-generated products of uncertain social, economic, and environmental worth. Across the stage, the National Institutes of Health, the developers of BST, and some producers' organizations, argue the domestic and international economic validity as well as human and animal safety of the compound. One senses at times that the future of farming, governmental legiti- 
macy, scientific freedom and progress and the survival of corporate America are all on the line. Interestingly, it has been stated that had the creators of BST known how it would be received and handled by governments and the creators themselves, an alternative such as porcine somatotropin (PST) would have been promoted in the first place. However, as some social scientists and ethicists have noted, it is not simply a strategic error in not considering the potentially controversial consequences of research and product-development, it is an ethical one as well, in failure to have considered some farmers', animal activists, and the larger consuming public's perceptions and values.

Serving agriculture through productionism, rationalizing agriculture through "big science" and emphasizing efficiency (under a narrow economic definition of terms) have remained the reigning mission and strategy of public agricultural research, as well as the dominant direction of private, corporate research. American consumers have benefitted by having the lowest food-to-income ratio in the world. The technologies that have been developed, from biotechnologically-engineered plant varieties to agrichemicals to computer-driven irrigation systems and sophisticated post-harvest transport, wholesaling and retailing systems-and now BST -are heralded as having allowed agriculturalists to all-but-overcome the inherent risks involved in farming. There is little doubt that the spread of these research products into less-developed nations, and the ensuing "Green Revolution" which transformed not only agriculture but whole societies, have produced great benefits for many people.

In our case study, a critique of productionism underlies the challenge to BST. It is as well a critique of technophilia, and perhaps to the utilitarian ethical philosophy which provides it the best justification. The challenge is far from univocal or even articulate in the actual public arena, coming as it does from an eclectic collection of environmentalists, family-farm advocates, the Foundation on Economic Trends, and the like. Nevertheless, it is there: Why not BST? The intriguing thing about the "case of BST" is how quickly and deeply the ethical question of "how to use" BST leads to "why new techniques," ultimately to, what kind of people are we and what kind of society do we want?

Over and above agriculture and agricultural research, many features of "modern" society continue to be challenged from a diverse array of thinkers. Productionism, and productionist-oriented technical change have done wonderful things, but at great individual and societal expense. More is no longer better, if it ever were.

The anti-productionist critique may overstate the case. Moreover, in the context of an appraisal of "the case of BST" the issue may seem grossly out of place. BST is, after all, only a single product, affecting only a single, small sector of a significant but hardly history-moving industry. 